\title{
Transport Mechanism of the Anthropogenic Lead Along 140 Near Barstow, California
}

Although anthropogenic lead contamination in US roadside environments drastically reduced with the ban of leaded fuel additive, lead that was deposited during the leaded gasoline era continues to be an environmental concern because of its long-term toxicity. Wind-blown dusts from the road, vehicles splashing water, and surface runoff water from the road have been identified in previous studies as the transport mechanisms of contaminants in roadside environments. This study investigates the extent of the anthropogenic lead contamination in the roadside soil environment on a segment of Interstate 40 in California east of Barstow, as a function of depth and distance from the road and its transport mechanism. These soils are sandy and typically dry with periodic flooding two to three times a year. They were exposed to lead emissions from vehicles for more than 54 years.

For this study, soil samples were analyzed using Microwave Plasma Atomic Emission Spectrometry (MP-AES). Soil samples were collected at the distance of 20, 40, 60, 100, 250, and $320 \mathrm{~m}$ away from the road margin and at depths of $0-15,20$, and $50 \mathrm{~cm}$. The ground surface profile gently sloped away from the road. Background concentration level is about $10 \mathrm{ppm}$ and the highest concentrations are up to 20 times higher than background. Total lead concentration generally decreases with the increasing depth and distance from the road. Highest lead concentration is mainly in the top soil layer. We compared lead levels in ground profiles sloping towards and away from the road to begin evaluating the role of surface runoff. 